\title{
Recurrence of a 30-years old leukemic clone ten years after allogeneic transplant: Azacitidine and donor lymphocyte infusion are an effective strategy to restore the graft-versus leukemia effect
}

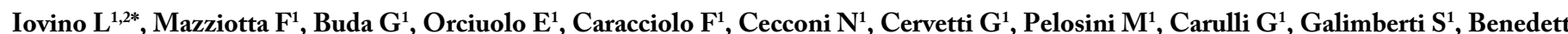
$\mathrm{E}^{1}$ and Petrini $\mathrm{M}^{1}$

${ }^{1}$ Hematology Division, Pisa University Hospital, Pisa, Italy

${ }^{2}$ Dudakov Lab, Program in Immunology, Fred Hutchinson Cancer Research Center, Seattle, WA, USA

Demetilating agents, such as Decitabine and Azacitidine (Aza), have been reported as effective salvage therapy for relapsed acute myeloid leukemia (AML) and myelodysplastic syndromes (MDS) $[1,2]$. There is evidence that treatment with demetilating agents may prime the donor lymphocyte infusion (DLI) by enhancing the graftversus leukemia effect $(\mathrm{GvL})$ in patients who relapse after allogeneic hematopoietic stem cell transplantation (HSCT) [3]. Herein, we report the case of a 40-year-old woman who had previously donated hematopoietic stem cells for her sister, diagnosed with MDS/AML twenty years before; the patient's sister experienced clinical recurrence of AML 18 years after HSCT, in presence of a full-donor chimerism on bone marrow (investigated by microsatellite analyses). This finding led us to investigate the donor, which showed leukopenia and macrocitic anemia of new onset. The morphologic examination (March, 2005) of the donor's bone marrow showed a $15 \%$ infiltrate of immature myeloid precursors (immunophenotyping: 52\% of the cells CD13+, 53\% CD33+, 17\% CD34+, 16\% CD33/CD34+, 1\% CD14+, 51\% CD3+ and $65 \% \mathrm{CD} 5+)$. The search for recurrent MDS/AML mutations by polymerase chain reaction and conventional cytogenetic analysis were both negative. The patient was diagnosed with myelodysplastic syndrome (MDS) RAEB-2, IPSS score high (2.5). The patient's sister was thus diagnosed with donor-derived MDS/AML and received a course of re-induction chemotherapy followed by second HSCT from a matched unrelated donor (see also) [4], but she died due to relapse three months after the second HSCT. Her sister, the donor of the first transplant, was strictly followed-up; during the following six months, the blast number increased to $25 \%$, and we decided to administer to her eight courses of subcutaneous Aza (day 1-6 $100 \mathrm{mg} / \mathrm{die}$ ) as induction therapy. A bone marrow aspiration in January 2006, showed a partial response ( $7 \%$ of blasts). Given the young age, the high-risk MDS, and the absence of other medical conditions, the patient was candidate for receiving allogeneic hematopoietic stem transplantation.

In January 2006, she was conditioned with myeloablative regimen consisting in busulfan $(160 \mathrm{mg} /$ die for 4 consecutive days, splitted in four daily doses) and cyclophosfamide (3600 $\mathrm{mg} /$ die in two consecutive days, split in five daily doses). The prophylaxis for acute graft-versus host disease (GvHD) consisted of: anti-thymocyte globulin (ATG) the day before transplant $(30 \mathrm{mg} / \mathrm{Kg})$; metotrexate $(24 \mathrm{mg}$ on day +1 , and
$16 \mathrm{mg}$ on days $+3,+6,+11$ ); and intravenous cyclosporine from day -2 to stem cell infusion followed by oral administration (target of 150-250 $\mu \mathrm{g} / \mathrm{l}$ on peripheral blood). At day 0 , the patient received hematopoietic stem cells and CD3+ lymphocytes, apheretically collected from peripheral blood, from a full-matched (6/6) unrelated donor (28-yearsold, male; 0 pos; CMV neg). Due to major AB0 incompatibility, the patient underwent plasmapheresis the day before and two days after transplant, and the graft was treated with a buffy-coat depletion of erythtocytes before the infusion. The patient did not develop any serious complication after transplant, and the engraftment of neutrophils occurred 19 days after transplant. Full-donor chimerism on peripheral lymphocytes was reached at day +60 . At day +57 after transplant, the patient developed CMV reactivation, treated with oral valgancyclovir (900 mg bid) until CMV load reached undetectable levels. In May 2006, the bone marrow aspiration showed the obtainment of complete remission. The patient showed mild cutaneous rash and joint pain in July, 2006 (day +180$)$, with no need of steroid administration. She tapered the oral cyclosporin after day +100 and remained in complete remission and good clinical conditions.

In January 2015, nine years after receiving HSCT, the patient reported astenia. Peripheral blood counts showed anemia and thrombocytopenia. A bone marrow blood aspiration showed $22 \%$ of blasts with the same features of the diagnosis (flow cytometry: CD34+, CD13+, CD33+, CD117+); concomitantly the patient also lost the full-donor lymphoid chimerism and showed an increased expression of WT1 by quantitatve PCR (287 copies/10.000 copies of ABL1). Since the late relapse after HSCT, we decided to treat the patient again with subcutaneous Aza (day 1-6 100 mg/die); after two cycles of Aza, well tolerated and without any adverse event, the patient received DLI from the same donor of the HSCT: (i) $3.0 \times 10^{\wedge} 6 \mathrm{CD} 3+/ \mathrm{Kg}$; ii) DLI $1.75 \times 10^{\wedge} 7$; iii) $3.04 \times 10^{\wedge} 7 \mathrm{CD} 3+/ \mathrm{Kg}$ ) in March, 2015. She received a third cycle of

${ }^{\star}$ Correspondence to: Lorenzo Iovino, Dipartimento Area Medica, Hematology division, Edificio 11 piano terra, Ospedale S. Chiara, via Roma 57, 56121, Pisa, Italy, Tel: +39 050993488, Fax: +39 050993488, E-mail: iovino-lorenzo@tiscali.it

Received: October 15, 2018; Accepted: October 29, 2018; Published: October 31,2018 
Iovino L (2018) Recurrence of a 30-years old leukemic clone ten years after allogeneic transplant: Azacitidine and donor lymphocyte infusion are an effective strategy to restore the graft-versus leukemia effect

Aza after the DLI. The blood counts recovered normal levels, and the bone marrow evaluation after Aza and DLI showed a new obtainment of the complete remission, with the recovery of full-donor both myeloid and lymphoid chimerism. Furthermore, the WT1 expression on bone marrow blood showed normal levels. The patient developed cutaneous and muscular chronic cGvHD, for which received several lines of therapy (steroid, photoapheresis, ibrutinib, ruxolitinib) with clinical response (from grade 4 to grade 2). At the last follow-up visit (October, 2018), the patient still maintained the complete remission, with mild GvHD clinical symptoms.

In our opinion, this case report is of interest for many reasons: first, the clone responsible for MDS/AML was, most likely, already present 30 years ago in the bone marrow of the patient, at the moment of her donation for the sister's transplant. Second: the MDS/AML clone clinically appeared at the same time both in donor and recipient, as though an inner clock was present in the leukemogenic mechanism. Third: the MDS/AML was successfully treated in the patients with a chemotherapy-free approach two times, ten years apart from each other. Fourth: the clearance of leukemia blasts by an immune effect of donor-derived lymphocytes was primed with Aza alone in both cases. MDS are a family of hetereogeneous clonal disease: however, there is a clonal evolution of the disease that requires the sequence of several mutations in hematopoietic stem cells, and this process requires years [5]. It is of interest that the morphological and immunophenotipical features of the blasts remained the same from the diagnosis to the relapse; this can partially explain the response to the same treatment ten years later, but it seems difficult to explain the escape of the residual disease from the immune surveillance long time after HSCT only basing on the phenotype features. Novel germline mutations in genes involved in maturation and differentation, such as DDX41 [6], have been recently described in families with multiple cases of hematological malignancies [7]. Very late relapse of leukemia has been described even 10 or 20 years after HSCT [8], suggesting a plastic longterm modulation of the immune surveillance against residual cancer cells. In this sense, demetylating agents may help in restoring immune control over leukemic cells by depleting myeloid-derived dendritic suppressor cells [9] and by sensitizing the tumor cells to the cytotoxic effect of T lymphocytes [10]. Demetylating agents have been shown to be effective in preventing relapse in high-risk MDS and AML after transplant in several studies $[11,12]$, and they have been adopted to treat effectively the relapse as single agent or in association with other drugs (such as midostaurine) [13] and DLI [14]. The use of Aza in MDS patients is associated with profound immunological changes [15]. In the post-allo-HSCT setting, Aza is of great interest in high risk patients given that it could act as immunomodulator with the possibility of diminishing GvHD through this action on the expression of the FOXP3 Treg-specific demethylated region (TSDR), which is methylated in hematologic malignancies, is crucial for the expression of FOXP3 [16]. The prevention of GvHD after DLI is also an important goal, since up to $60 \%$ of patients can develop GvHD after DLI [17]. Although linked to an enhancement of the GvL effect [18], the development of severe GvHD entails the re-initiation of immunosuppressive prophylaxis and high-dose steroids if required [19]. This scenario, if prolonged, might impair the GvL effect and increase the infection risk, particularly from opportunistic pathogens. Furthermore, in a very large retrospective study, chronic GvHD was associated with the prevention of late relapse only in patients who received HSCT for chronic myeloid leukemia, but not for MDS and AML [20]. Aza has been described not only to prevent
GvHD, but also to enhance the DLI-mediated GvL in AML patients through an anti-WT1 effect (3). For all this reasons, demetylating agents seem very promising in the management of MDS/AML highrisk patients after HSCT, either in primary prevention and in case of relapse as a bridge to DLI.

\section{References}

1. Kuendgen A, Muller-Thomas C, Lauseker M, Haferlach T, Urbaniak P, et al. (2018) Efficacy of azacitidine is independent of molecular and clinical characteristics - an analysis of 128 patients with myelodysplastic syndromes or acute myeloid leukemia and a review of the literature. Oncotarget 9: 27882-27894. [Crossref]

2. Stahl M, DeVeaux M, Montesinos P, Itzykson R, Ritchie EK, et al. (2018) Hypomethylating agents in relapsed and refractory AML: outcomes and their predictors in a large international patient cohort. Blood advances 2: 923-932. [Crossref]

3. Ishikawa T, Fujii N, Imada M, Aoe M, Meguri Y, et al. (2017) Graft-versus-leukemia effect with a WT1-specific T-cell response induced by azacitidine and donor lymphocyte infusions after allogeneic hematopoietic stem cell transplantation. Cytotherapy 19 514-520. [Crossref]

4. Orciuolo E, Azzara A, Bandini G, Galimberti S, Bonifazi F, et al. (2004) Contemporaneous appearance, 18 years after allogeneic bone marrow transplantation, of myelodysplastic syndrome in the patient and the donor. Bone Marrow Transplant 33: 859-861. [Crossref]

5. Makishima H, Yoshizato T, Yoshida K, Sekeres MA, Radivoyevitch T, et al. (2017) Dynamics of clonal evolution in myelodysplastic syndromes. Nature genetics 49: 204212. [Crossref]

6. Lewinsohn M, Brown AL, Weinel LM, Phung C, Rafidi G, et al. (2016) Novel germ line DDX41 mutations define families with a lower age of MDS/AML onset and lymphoid malignancies. Blood 127: 1017-1023. [Crossref]

7. Koeffler HP, Leong G (2017) Preleukemia: one name, many meanings. Leukemia 31: 534-542. [Crossref]

8. Norkin M, Uberti JP, Schiffer CA (2011) Very late recurrences of leukemia: why does leukemia awake after many years of dormancy? Leuk Res 35: 139-144. [Crossref]

9. Zhou J, Yao Y, Shen Q, Li G, Hu L, et al. (2017) Demethylating agent decitabine disrupts tumor-induced immune tolerance by depleting myeloid-derived suppressor cells. Journal of cancer research and clinical oncology 143: 1371-1380. [Crossref]

10. Zhang Z, He Q, Tao Y, Guo J, Xu F, et al. (2017) Decitabine treatment sensitizes tumor cells to T-cell-mediated cytotoxicity in patients with myelodysplastic syndromes. American journal of translational research 9: 454-465.

11. Graef T, Kuendgen A, Fenk R, Zohren F, Haas R, et al. (2007) Successful treatment of relapsed AML after allogeneic stem cell transplantation with azacitidine. Leukemia research 31: 257-259. [Crossref]

12. Ganguly S, Amin M, Divine C, Aljitawi OS, Abhyankar S, et al. (2013) Decitabine in patients with relapsed acute myeloid leukemia (AML) after allogeneic stem cell transplantation (allo-SCT). Ann Hematol 92: 549-550. [Crossref]

13. Cooper BW, Kindwall-Keller TL, Craig MD, Creger RJ, Hamadani M, et al. (2015) A phase I study of midostaurin and azacitidine in relapsed and elderly AML patients. Clinical lymphoma, myeloma \& leukemia 15: 428-432. [Crossref]

14. Ghobadi A, Choi J, Fiala MA, Fletcher T, Liu J, et al. (2016) Phase I study of azacitidine following donor lymphocyte infusion for relapsed acute myeloid leukemia post allogeneic stem cell transplantation. Leuk Res 49: 1-6. [Crossref]

15. Costantini B, Kordasti SY, Kulasekararaj AG, Jiang J, Seidl T, et al. (2013) The effects of 5 -azacytidine on the function and number of regulatory $\mathrm{T}$ cells and T-effectors in myelodysplastic syndrome. Haematologica 98: 1196-1205. [Crossref]

16. Cooper ML, Choi J, Karpova D, Vij K, Ritchey J, et al. (2017) Azacitidine mitigates graft-versus-host disease via differential effects on the proliferation of $t$ effectors and natural regulatory T cells in vivo. Journal of immunology. 198: 3746-3754. [Crossref]

17. Porter DL, Roth MS, McGarigle C, Ferrara JL, Antin JH (1994) Induction of graftversus-host disease as immunotherapy for relapsed chronic myeloid leukemia. $N$ Engl J Med 330: 100-106. [Crossref]

18. Marks DI, Lush R, Cavenagh J, Milligan DW, Schey S, et al. (2002) The toxicity and efficacy of donor lymphocyte infusions given after reduced-intensity conditioning allogeneic stem cell transplantation. Blood 100: 3108-3114. [Crossref] 
Iovino L (2018) Recurrence of a 30-years old leukemic clone ten years after allogeneic transplant: Azacitidine and donor lymphocyte infusion are an effective strategy to restore the graft-versus leukemia effect

19. Orti G, Barba P, Fox L, Salamero O, Bosch F, et al. (2017) Donor lymphocyte infusions in AML and MDS: Enhancing the graft-versus-leukemia effect. Experimental hematology 48: 1-11. [Crossref]
20. Boyiadzis M, Arora M, Klein JP, Hassebroek A, Hemmer M, et al. (2015) Impact of chronic graft-versus-host disease on late relapse and survival on 7,489 patients after myeloablative allogeneic hematopoietic cell transplantation for leukemia. Clinical cancer research 21: 2020-2028. [Crossref]

Copyright: $(02018$ Iovino L. This is an open-access article distributed under the terms of the Creative Commons Attribution License, which permits unrestricted use, distribution, and reproduction in any medium, provided the original author and source are credited. 